dition that the residual anomalies, $A$, have only a very limited influence, which implies that the integral

$$
\psi=\iint(B-R)^{2} \mathrm{~d} x \mathrm{~d} y
$$

over the area within which the regional anomaly is required, is a minimum. A complete description of the method was presented, and illustrated by practical examples.

The discussion which followed these two papers on gravity was very lively, and some speakers, led by Prof. Vening Meinez, expressed their doubts of the real practical value of the various methods which attempt to eliminate the 'regional effect' from the Bouguer picture. Dr. Rosenbach, in his reply, emphasized the importance of an appreciation of the scale of the problem in gravity prospecting. It must be realized that a very close network of stations is adopted, and that the modern gravimeter can be read with an accuracy of at least 0.1 milligal.

Prof. K. Jung (Germany) described two elegant geometrical constructions for determining the approximate positions of buried bodies of simple form from their gravity or magnetic anomalies. He explained that these constructions were developed for use by geologists and others with a restricted mathematical background who require to assess roughly the results of a geophysical survey. $\mathrm{He}$ described also a simple mathematical development of Nettleton's method of determining near-surface densities from a series of gravity observations along a profile over a topographical feature.

The telluric current method of prospecting has been developed and used with considerable success by French geophysicists. A paper by Mr. M. Mainguy and Mr. A. Grepin (France), describing some practical examples of interpretation of telluric maps obtained in Languedoc (south-east France), was written from the point of view of a geologist, and was therefore of particular interest. The results of telluric surveys in the Beziers and Alés-Maruéjols basins and the Lunel area were described, and compared with gravity and seismic investigations in the same areas.

The outstanding feature of this particular geophysical work is that, in general, the telluric method has apparently furnished more detailed and accurate information than any other method. In the case of the Alés-Maruejols survey, the results of the telluric observations contradicted to a considerable extent the prevailing geological ideas and the findings of other geophysical methods; but subsequent drilling evidence confirmed the aceuracy of the telluric interpretation and resulted in the discovery of oil. In the Beziers basin the telluric results agreed quite well with the gravity findings, but, in common with the seismic work, the method was unable to secure detail from the depths required. The survey in the Lunel area was very difficult to interpret, but despite this the telluric method appears to be the most promising one to employ.

Mr. G. Kunetz (France) dealt with the problem of eliminating the effect on telluric observations of stray earth currents originating from installations such as electric railways, tramway systems, etc. For surveys where the source of disturbance is, say, a large industrial town at a considerable distance, it is possible to represent the disturbing field approximately by a function the parameters of which can be determined experimentally. A 'regional anomaly' map can thus be produced. Where the disturbing source, or sources, are in the immediate proximity, and the parasitic currents are liable to violent fluctuations, much more laborious methods are required, involving numerous field measurements. It speaks highly of the work of our French colleagues that it has been found possible to produce telluric maps of practical value in such difficult circümstances.

D. T. Germain-Jones

${ }^{1}$ Geophysics, 16, 1, 29 (1951).

\section{CONFERENCE ON FERTILITY}

$T$ HE scientific proceedings of the third annual Conference on Fertility, held by the Society for the Study of Fertility in London during June 27 and 28, were opened by Dr. Carl G. Hartman (United States), who presented formidable evidence for the theory of germ-plasm defect as a major cause of foetal wastage. His early studies on the aplacental opossum; in which he found some 10 per cent of all the developing eggs to be grossly faulty, led him to favour the view put forward by Streeter-that early death of the embryo was due mainly to defective germ plasm-rather than the older idea of Mall that implantational defects were chiefly responsible. Later studies on mouse eggs, using intra-vital staining techniques, supported the same view by demonstrating, in many instances, dead and living blastomeres within the same zygote. He referred also to the recent studies by Hertig and Rock of early human ova; in none of the cases wherein these were abnormal did the authors find any evidence of endometrial deficiencies, although Dr. Hartman admitted that Hughes has claimed that a lack of a glycogen could be demonstrated in the endometrium in some cases of early abortion.

Prof. S. A. Asdell (United States) gave a provocative contribution. on the effect of intelligence upon fertility, basing his conclusions on a study of the pedigrees of royal houses. Although the assessment of 'intelligence' was made as objective as possible, he admitted the possibility of many sources of error. Nevertheless, with the exception of genius, which appears to make its own law's, definite correlations appeared to exist, many of which were contrary to popular beliefs. Thus, although the incidence of inbreeding decreased with rising intelligence, the proportion of childless marriages was highest with least intelligence and smallest with average intelligence, and the number of children in the family was highest with average intelligence. It seemed that Nature favoured the average in intelligence, as in most other biological attributes. Another finding was that, contrary to Galton's view, the families of only children of high intelligence (judges who had been elevated to the peerage in Stuart and Georgian times) tended to be large, averaging five to six offspring. Naturally, this paper evoked lively discussion.

Prof. S. Zuckerman (Birmingham) reviewed the cellular components of the ovary, particularly from the point of view of their plasticity. He referred to his own recent work, which leads him to conclude that, in the rat at least, no formation of new oocytes from the germinal epithelium occurs in the adult. $\mathrm{He}$ considers the function of the germinal epithelium to be mainly protective; it is highly phagocytic and resilient, continually changing in size and shape as follicles mature and corpora lutea develop and regress. He stressed its sensitivity to trauma, to which it responds vigorously by the formation of 
ingrowths and outgrowths. The other highly plastic element of the ovary is the theca interna cell, which transforms from a fibroblastic cell into an epithelioid secreting cell, luteinizes to become-very likely--the only functional endocrine element of the corpus luteum, and finally can become transformed back into a fibroblastic structure.

Dr. Henri Bayle (Paris) discussed spermatophagia in the human epididymis in cases of excurrent duct obstruction and showed slides of spermatorrhagerupture of the epididymal tubules through excessive internal pressure, with outflow of spermatozoa into the peritubular spaces, leading to obliteration of the epididymal canal. He then demonstrated his film showing the operative technique of vaso-epididymostomy; the beauty and lucidity of this film are beyond description. Dr. Bayle does not perform testicular biopsy first, but prefers to incise the head of the epididymis after having mobilized the testicle; if moving spermatozoa are seen in the epididymal fluid, he proceeds with the operation, provided patency of the vas deferens can be demonstrated. He uses seven sutures of fine tantalum wire to anastomose the vas to the epididymis. Delicacy of touch and the avoidance of trauma are the prime requisites of success in this difficult operation. Out of 143 cases explored surgically, anastomosis was found impossible in thirty cases, and in a further six congenital absence of the vas was discovered. Vaso-epididymostomy was performed bilaterally in sixty cases, and unilaterally in forty-five; in a further four cases anastomosis of the vas deferens direct to the testicles was attempted. Of sixty-five surgically satisfactory cases, the azoospermia was cured in forty-five (66 per cent), twenty of these men producing in all thirty-two children. This rate of success, of course, is far better than any other surgeon has achieved.

The morning of June 28 was devoted to a symposium on spermatozoan morphology; this was opened by Prof. L. Harvey (Exeter), who gave a review of spermatogenesis and spermateliosis. The National Institute for Medical Research team of workers (C. F. Challice, P. E. Lake, E. J. C. Polge and J. Smiles) reported ultra-violet microscopy studies on living fowl germ cells and electronmicroscope studies of mouse and rabbit spermatozoa. They showed how the Golgi zone of the fowl spermatid developed into the acrosome. The tail filament was found to be motile from the earliest stage, the tail granule being the source of motility. Chromosome material aggregates, becoming a homogeneous mass within the nuclear membrane. It then elongates, later to shrink, leaving behind a free portion of the nuclear membrane, thus forming the manchette which later forms a rigid tube around the first part of the tail. Considerable advances in our knowledge of the morphology of rabbit and mouse spermatozoa have been afforded by the technique developed by these workers of cutting sections $0.2 \mu$ thick followed by electron microscopy. There is strong evidence for a double spiral structure of the mid-piece and tail around the axial filament, all within a fine outer membrane. The axial filament contains nine fibrils arranged circularly around a central one, and there appears to be a flange running lengthwise down the tail.

Mr. Geoffrey Grigg (Cambridge) also contributed electron-microscope studies on fowl spermatozoa, his findings being mainly in agreement with those of the previous speakers. The apical cap dissolves in distilled water, leaving the apical spine partly embedded in the head. He has regularly found eleven fibrils in the axial filament-two central and nine outer. There seems to be an inner core to each fibril which is more elastic and more resistant to tryptic digestion than the surrounding material. Dr. Bayle showed electronmicroscope photographs of human spermatozoa. Dr. John McLeod (United States) discussed spermatozoan morphology in relation to human fertility and, as a result of his large-scale studies, he has come to the conclusion that little correlation between sperm morphology and fertility can be discovered in the human. Poor morphology is commonly associated with poor motility - which has a very definite bearing on fertility-but otherwise, provided the sperm density exceeds 20 millions per $\mathrm{ml}$. and the percentage of active cells is not much below 40 , fertility seems to depend mainly upon the quality of sperm motion.

Dr. John Wilkinson (Exeter) described the effects of aspermy virus upon nuclear behaviour in solanaceous plants. In the pollen and embryo sac mother cells, the pachytene threads become disorganized in the prophase of meiosis and the nucleoli are multiplied. Some of the chromosomes fail to pair, leaving behind univalents at metaphase and anaphase. This probably accounts for the 25 per cent diminution in seed production shown by affected plants. It was suggested that a competition may exist between the virus and the chromonematal material of the chromosomes for ribose-nucleic acid. Mrs. C. Harvey (Exeter) said she had made similar observations on testicular biopsy material from subfertile men, having also noted collapse of the chromonemata at prophase and loose and lagging chromosomes at metaphase and anaphase. This seemed to suggest a possible viral etiology for some cases of human male infertility.

In the last two papers, Dr. F. X. Gassner (United States) showed that the rate of fructolysis in seminal fluid is better correlated with the breeding efficiency of bulls than the conventional criteria of seminal analysis, and Dr. E. W. Macmillan (Liverpool) described the vascular pattern of the epididymis in the rat and the sequence of changes in the epididymis and testis following interruption of the superior epididymal and accessory capital arteries; the vasa efferentia became packed with spermatozoa, which led to their gross enlargement and to severe degenerative changes within the testis, while the caput epididymis underwent necrobiosis followed by obliterative fibrosis.

\section{EMULSIONS AND FILMS SYMPOSIUM AT SHEFFIELD}

$T$ THE British Society of Rheology organized a symposium on "Emulsions and Films" which was held in the University of Sheffield during March 28-29. All the papers were followed by discussion, and on the second dry the meeting visited the chemistry laboratories of the University and inspected the apparatus used by the speakers at the meeting.

In the first paper, Dr. A. S. C. Lawrence pointed out that emulsions are always placed in a separate category of colloids as liquid-in-liquid systems-a classification to which objection can be made on two grounds : the fact that the liquid state of the disperse phase makes possible dispersion by shaking is of no fundamental importance (it is not even true for 